\title{
Does the SMS Language Have an Effect on Teenage Spelling? - A Study Conducted on a Selected Group of Students Studying in Colombo
}

\section{Mayanthi Kulatunga Jayakody*}

Department of Language Studies, Faculty of Humanities and Social Sciences, Open University of Sri Lanka, Nawala, Sri Lanka

\section{Abstract}

The focus of this research is to find out whether the use of SMS language has a link to the spelling of school going teenagers (within the age limit of thirteen and nineteen years) when writing in English according to the accepted form in schools. Mobile phones are undoubtedly the most commonly used method of communication in the world today. The free availability of SMART phones could be considered as one of its causes. Such phones are equally popular among adults as well as teenagers. Seemingly, the preference of the teenagers is inclined more towards text messaging than voice. Among them, there are many who use abbreviated terms commonly known as SMS language for texting. As Seda (2013) affirms, this particular discourse is also called by other names such as 'textese' and 'textspeak'. The obvious familiarity of these children with the particular usage makes one wonder whether it would affect their spelling when involved in their studies. As a result, this research explores whether the extensive use of SMS language affects the knowledge of formal English spelling of such teenagers.

This study has derived its data from a group of teenagers attending two local private schools and an international school

\footnotetext{
* Correspondence should be addressed to Mayanthi Kulatunga Jayakody Email: mayanthi2006@yahoo.com

iD https: / / orcid.org/0000-0001-9568-553X

(Received 30th September 2017; Revised 30th November 2017; Accepted O7th December 2017) (C) OUSL
} 
within the city limits of Colombo and also a few teachers belonging to both these schools. The research tools that were utilized were observation and a questionnaire that collected quantitative as well as qualitative data. This paper, which includes a background history of the mobile phone and text messaging, a list of popular SMS abbreviations in the "SMS discourse" (Mendis, 2006), the methodology and the recommendations based on the findings would hopefully be helpful to English teachers when considering the causes of good or bad spelling of schooling children especially the ones who are within the age limit of thirteen and nineteen years (commonly referred to the teenagers in this study).

Key words: Text messaging, SMS discourse, spelling errors, abbreviated terms, unabbreviated English words, formal English words

\section{Introduction}

Over the years, the needs of a human being have expanded and the mobile phone seems the new entrant to the list. According to the Cooney Centre report Pocket of Potential (2009), the then existing world population of mobile phone users had been approximately four billion. It further states that the mobile phone penetration has reached almost 100 percent. The lack of infrastructure and inefficiency has thwarted the installation of landlines in developing countries and has increased this situation (Blanchard \& Moore, 2010). Since 3rd April, 1973 when the Motorola employer Martin Cooper made the first mobile phone call from Manhattan to the headquarters of Bell Labs in New Jersey, USA, this technological marvel has reached unimaginable heights.

According to Bates (2015), studies had exposed that by 2015, almost one in four teenagers was indulged in using mobile phones. Unarguably, they have become a necessity due to many reasons such as updating their guardians on their whereabouts, balancing studies and co-curricular activities as well as communicating in general. Incidentally, their communication is mainly performed through text messaging and many of them adhere to the usage of abbreviated words, more popularly known as SMS language. 
The very first text message was a Christmas greeting by the British engineer Neil Papworth to Richard Jarvis on $3^{\text {rd }}$ December, 1992 (Seda, 2013). Ever since then, text messaging has evolved from being a mere SMS (Short Message Service) to vast communication practices such as Facebook, Messenger, Twitter, Whatsapp Viber and Instagram. Text messaging could be either performed in normal written language or with abbreviations termed as SMS Discourse (Mendis, 2006). 'Textese' and 'textism' (Seda, ibid) are some of the other terms which are popularly used for the same. Evidently, such discourse is different to the formal English the students are expected to utilize in their studies. By formal, what is meant here is the British English which is the accepted form of English in the Sri Lankan school curriculum. Based on the popular public assumption, SMS language could influence the spelling of school going students since there is a notable but subtle difference between the two languages mentioned. However, scholars such as Seda (2013) and Drouin \& Davies (2009) refute such beliefs stating that SMS language somewhat resembles the spelling of children who are at the initial stage of learning to spell. As a result, this paper intends to find out which of these stands holds true by focusing on a selected group of students representing a certain socio-economic class in Colombo.

\section{Literature Review}

Text messaging and its relativity to teenage literacy is not a novice area to the field of research. In Sri Lanka, Mendis (2006) has done a study on the features of 'SMS discourse' in which she speaks of its influence on literacy. According to Mendis, SMS discourse contains colloquial Sri Lankan English in the form of codeswitching, tag questions, reduplications, interjections and idiomatic or formulaic expressions. Furthermore, there are abbreviations (' $u$ ' for 'you' and ' $b$ ' for 'be'), intentional misspelling ('wats' for 'what's' and 'dis' for 'this'), direct phonetical spelling ('shud' for 'should', 'ur' for 'you are' and '2moro' for 'tomorrow'), vowel deletion ('wld' for 'would' and 'thks' for 'thanks') and alphanumeric combinations (' $b 4$ ' for 'before') in abundance (a list of abbreviations popularly used in SMS discourse is included under 'Findings'). Mendis further asserts that sociolinguistic variables such as age, educational level, language proficiency and profession are visibly non-influential on this discourse. However, 
her paper does not discuss the possible effects this particular discourse has on spelling.

Blanchard \& Moore (2005) quoting Cooper (2005) state that a person's environment he/she is mostly exposed to has a direct influence on his/her learning. This includes the omnipresent mobile phones and mass media as well. Basically, they believe that this kind of exposure could be used positively to enhance their literacy skills. However, though this study is a broad outlook on the relationship between the digital world and learning, it does not focus on spelling per se which is a sub-literacy skill. Further, one could wonder whether the frequent indulgence in using abbreviated terms might be harmful for English spelling that is expected to be used in schools.

Seda (2013) quoting Drouin \& Davis (2009) says that the language mechanics used in SMS language could be compared to the spelling of youngsters who are still learning to spell. He further states that a majority of the public believes in SMS language leading to the deterioration of spelling largely due to the influence of what the media portrays to the world. Yet, negating this belief, Seda affirms that the present-day teenagers are inclined towards reading and writing to avoid being negatively affected by text messaging. $\mathrm{He}$ in fact states that messaging is currently considered as a favoured form of social communication among adults and teenagers alike. Based on Seda's affirmation, it is possible to assume that even if a person is extensively using SMS language, his spelling will not be affected provided he is an avid reader or/and a frequent writer.

McElroy (n.d), in order to justify the use of SMS discourse, points out that a 'texter' is compelled to use abbreviations as certain mobile phones allow only a limited amount of characters. However, this argument could be out ruled in today's context since most of the present day mobile phones are quite sophisticated and contain more capacity for a single text. In the meantime, Drouin \& Davis (2009) argue that language learnt over time is not easily forgotten or affected by such abbreviations. They also affirm that words with more complex structures are usually not converted into abbreviations.

Hogan, Gilbert, Leckington \& Morris (2012) state that most mobile phone users are in the habit of text messaging which is evident by 
the sights of people being glued to their phones. Contrary to Drouin and Davis' stance, they found out that many instructors of a particular college in the USA believe that text messaging has negative effects on students' writing skills. Yet, interestingly, they also discovered that most of the students switch from text language to the formal language they are expected follow in college. This proves that different scholars have varying opinions on text messaging and its effects on literacy.

Accordingly, SMS discourse has no strict rules. The words can be abbreviated according to the texter's wish. However, in which ever way the words are shortened, they are undisputedly different to the formal English spelling. Yet, there is no unanimous belief on whether SMS language affects spelling or not. Furthermore, in Sri Lanka, there are no published papers available on the effects of SMS language on teenage spelling. Further, the above mentioned empirical researches have been done exclusively in countries in which English is the mother tongue. Therefore, English being the second language of Sri Lanka, this paper may contribute in locating possible solutions for the perceived issues in spellings among schooling going children.

\section{Methodology}

This research focuses on whether the SMS language has an effect on how teenagers spell English words in school. Its main purpose is to find out whether the SMS discourse has an effect on the development of a teenager's knowledge on English spelling. This section will explicitly present how the said research was conducted including the research setting, samples and the sources, collection and analysis methods of data as well as the limitations pertaining to it.

This study includes a sample of twenty-six (26) teenage girls and boys who own mobile phones and who use SMS language plus four (04) English Literature teachers.

The teenagers are between the ages of 14 to 16 years. This purposive sample was selected in order to avoid 'late teens' that are on the verge of becoming adults. It included eighteen students (nine females and nine males) from local private schools and eight 
students (four females and four males) from an international school which are situated within the city limits of Colombo. They all offer English Literature as a subject for their Ordinary Level Examination (the local private school students for the local examination and the international school students for the London examination). The number of participants from the international school was less compared to the number from the local private schools as during the time of data collection they had completed their term end examinations and were not attending school on a regular basis.

The teachers were chosen on friendly basis thus making them a sample of convenience. An equal number of teachers were involved from both sectors of schools. The teachers who teach the said students were provided with the following passage which was read twice over. At the first instance, the students were asked to produce the text in SMS discourse while during the second reading they had to reproduce it in the formal English terms they use in their studies.

\section{The paragraph that was read out to the students:}

'Adolescents have a strong tendency to resist authority and therefore often want to do the opposite of what they are asked. This tied up with their desire to be recognized as individuals and they are breaking loose from shackles. They want to choose their own friends, clothes and books. The parents' reluctance to grant this independence and their effort to pry into the affairs of their children, their refusal to allow them a key so that they know when they come in, their failure to trust, all lead to friction. Another important reason for friction is that the adolescent is beginning to think for himself whereas previously he had he had accepted what his parents said. He now wants to have good reasons for them. When a child is being reprimanded and begins to try to explain his actions his father snaps, "Don't answer back".'

(Source: http://www.jirikihongan-kaiun.com/?page=1510608617)

There were several reasons as to why this particular paragraph was chosen. It contains frequently used words that are generally transcribed into SMS discourse such as 'have', 'to', 'are', 'and', 'be', 'from', 'for', 'now' and 'this'. It also has words which are occasionally used according to the relevant context like 'adolescents', 'tendency', 'individuals', 'loose', 'shackles', 
'independence', 'refusal' and 'reprimanded'. Yet, these terms too have been written as abbreviations by the selected texters.

The length of the paragraph was sufficient to hold the attention of the participants. Furthermore, the content of the passage is relevant to adolescents. Once the texts were written, both texts produced by each student were observed and compared extensively and a content study was done in order to locate any resemblance of the errors made in the formal English transcription with the production of the SMS discourse.

The passage was entered into the first row of a spreadsheet with a single word in each cell. The first column was confined to the students with double rows per each. The females were mentioned in pink colour and the males in blue. Every single misspelled word was entered in the relevant column in red colour in the first row of each student while its abbreviated counterpart was entered underneath (in the second row) in black.

The teachers were asked to answer a questionnaire based on their teaching experiences and their anonymity was strictly maintained.

\section{Findings}

During the transcription done in SMS language, most of the students had used the common versions for particular words while some had used slightly different versions for a single word. Nevertheless, they were all abbreviated versions of the original words.

The following table contains the abbreviated words used by the students along with the original words in formal English in the order of appearance. 
Table1. Abbreviations and their original terms

\begin{tabular}{|c|c|}
\hline $\begin{array}{c}\text { Word in unabbreviated } \\
\text { English }\end{array}$ & Word as an abbreviation \\
\hline Adolescents & adlsnc / adolsnce \\
\hline have & hv \\
\hline strong & strng \\
\hline therefore & there4 / thrfr \\
\hline want & wnt \\
\hline to & 2 \\
\hline the & $\mathrm{d} / \mathrm{da}$ \\
\hline opposite & oppste / opsite / oppst \\
\hline what & wat \\
\hline they & dey \\
\hline are & $\mathrm{r}$ \\
\hline this & dis / diz \\
\hline with & wid \\
\hline desire & dsire \\
\hline be & $\mathrm{b}$ \\
\hline recognized & recgnzd \\
\hline individuals & indvdls \\
\hline from & frm \\
\hline their & deir \\
\hline friends & frndz / frends \\
\hline books & buks \\
\hline
\end{tabular}




\begin{tabular}{|c|c|}
\hline and & $\mathrm{n} / \&$ \\
\hline grant & grnt \\
\hline this & $\operatorname{diz} /$ dis \\
\hline reluctance & reluctance \\
\hline independence & indepndnce \\
\hline effort & efrt \\
\hline allow & allw \\
\hline them & dem \\
\hline that & dat \\
\hline know & knw \\
\hline when & wen \\
\hline come & cum \\
\hline important & imprtnt \\
\hline for & $\mathrm{fr}$ \\
\hline beginning & beginin \\
\hline said & sed \\
\hline good & gud \\
\hline his & hiz \\
\hline father & fthr \\
\hline
\end{tabular}

Altogether, there were 106 spelling mistakes made by the total number of students. In other words, 106 pairs (the spelling error and the SMS counterpart) were entered on the spreadsheet. Out of those pairs, 50 were identical. As a result, there were 56 pairs which were dissimilar. Table 2 is an indication of these facts. Further, this observation was made in order to check the tendency 
of the students to make spelling errors that are identical to the SMS discourse.

Table 2. Instances of identical errors

\begin{tabular}{|l|c|}
\hline Total number of pairs of spelling errors and their & $\mathbf{1 0 6}$ \\
\hline Pairs of identical spelling & 50 \\
\hline Pairs of non-identical spelling & 56 \\
\hline
\end{tabular}

Figure 1 is used to provide a clearer picture of the facts shown in Table 2. The colour blue represents the number of identical pairs while red denotes the non-identical equivalents.

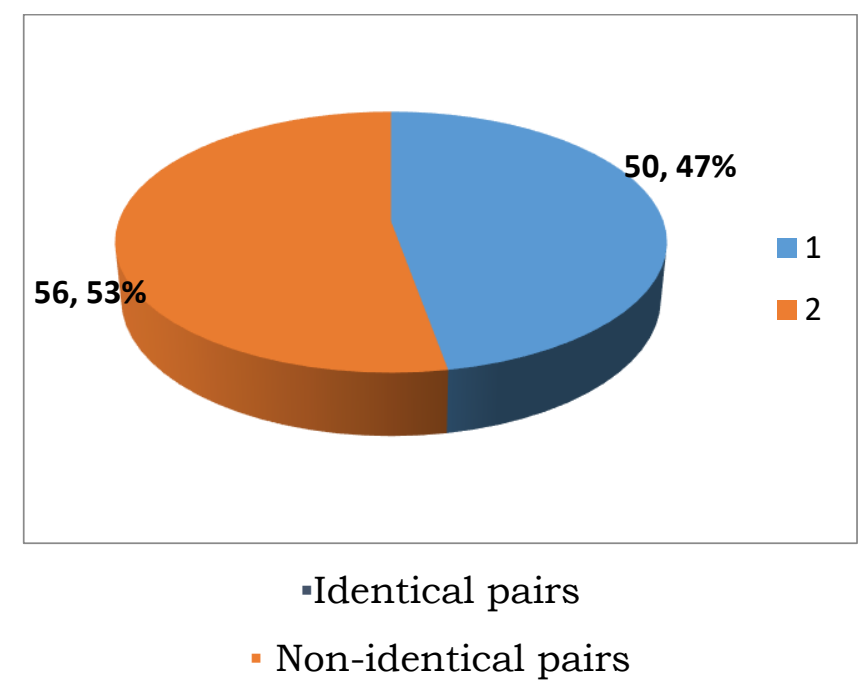

Figure 1. Instances of identical errors

Among the 50 errors which matched the SMS equivalent, only 1 word resembled the typical SMS language namely 'adolsnce'. This abbreviated version is mentioned in Table 1 . In other words, out of the 50 pairs, 49 did not resemble the typical SMS discourse but general spelling mistakes. This finding proved that there are no 
basic rules for SMS language and also that the spelling mistakes made by a majority of the students exhibit no relationship with the relevant abbreviated terms they use while texting.

Table 3. Instances of spelling errors written in typical SMS discourse

\begin{tabular}{|l|l|}
\hline Total number of pairs of identical spelling errors & $\mathbf{5 0}$ \\
\hline Number of errors written in SMS discourse & 1 \\
\hline Number of general errors which do not resemble & 49 \\
typical SMS discourse & \\
\hline
\end{tabular}

Figure 2 indicates the information provided in Table 2. The colour blue indicates the number of mistakes which were distinctive of SMS discourse and colour red represents the number of pairs which were identical yet did not resemble typical SMS terms.

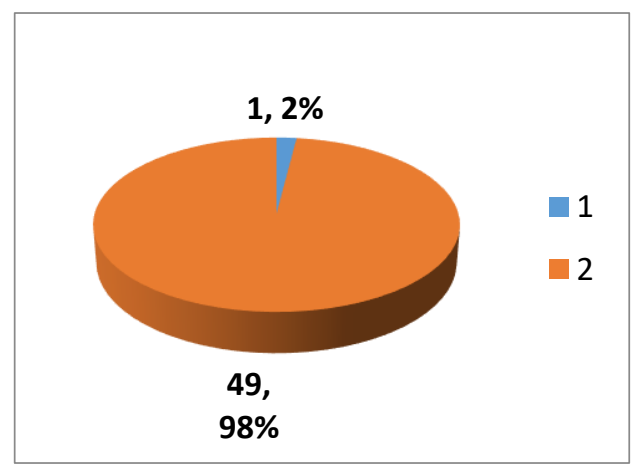

-Mistakes distinctive of SMS discourse

- Mistakes non-distinctive of SMS discourse

Figure 2. Instances of spelling errors written in typical SMS discourse

There were 2 other pairs namely 'lose' and 'there', which were used respectively for 'loose' and 'their' among the above mentioned 50 identical pairs of mistakes. Though they were correctly spelt 
words, they were considered as mistakes since they were used in the wrong context. This information is indicated in Table 4. This proved that there were few students who made spelling errors due to the lack of contextual knowledge.

Table 4. Instances of correct spelling but belonging to a different Context

\begin{tabular}{|l|c|}
\hline Total number of pairs of identical spelling errors & 50 \\
\hline Number of pairs of mistakes which were correctly spelt & 2 \\
\hline Number of pairs of mistakes which had totally wrong & 48 \\
Spellings & \\
\hline
\end{tabular}

This datum is illustrated through Figure 3 in which colour blue denotes the number of correctly spelt words but belonging to a different context while red represents the number of pairs which are anyway spelt wrong.

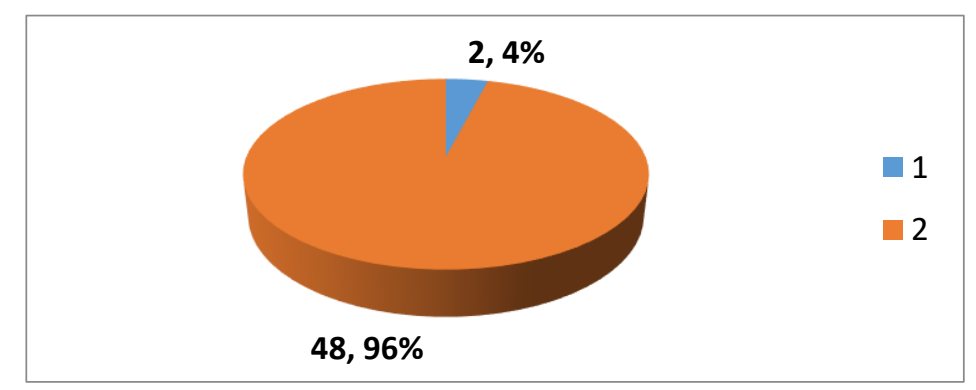

-Correctly spelt words but in a different context

" Pairs with totally wrong spelling

Figure 3. Instances of correct spelling but belonging to a different context 
As mentioned earlier, there were 18 participants from the local private schools and 8 from the international school. The total number of spelling errors made by the former was 94 while the latter made 12. The selected passage had a total of 145 words. The following tables indicate the figures of the total numbers of words and spelling errors made by the students of both sectors. The purpose of this table was to find out whether the type of school they attend has a connection to the number of spelling errors they make.

Table 5. Instances of spelling errors made by the students of local private schools

\begin{tabular}{|l|l|}
\hline $\begin{array}{l}\text { Total number of words produced by the } \\
\text { students }\end{array}$ & $145 \times 18=2,610$ \\
\hline Total number of errors & 94 \\
\hline Total number of correct words & $2,610-94=2,516$ \\
\hline
\end{tabular}

Table 6. Instances of spelling errors made by the students of the international school

\begin{tabular}{|l|l|}
\hline $\begin{array}{l}\text { Total number of words produced by the } \\
\text { students }\end{array}$ & $145 \times 8=1,160$ \\
\hline Total number of errors & 12 \\
\hline Total number of correct words & $1,160-12=1,148$ \\
\hline
\end{tabular}

The following Figures 4 and 5 respectively represent the data provided in Tables 5 and 6 with the relevant percentages. Blue indicates the amount of spelling errors and red, the correctly spelt words. 


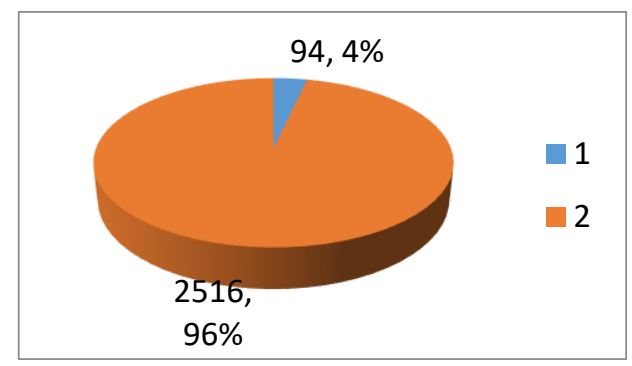

-Spelling errors

- Correctly spelt words

Figure 4. Instances of spelling errors made by the students of local private schools

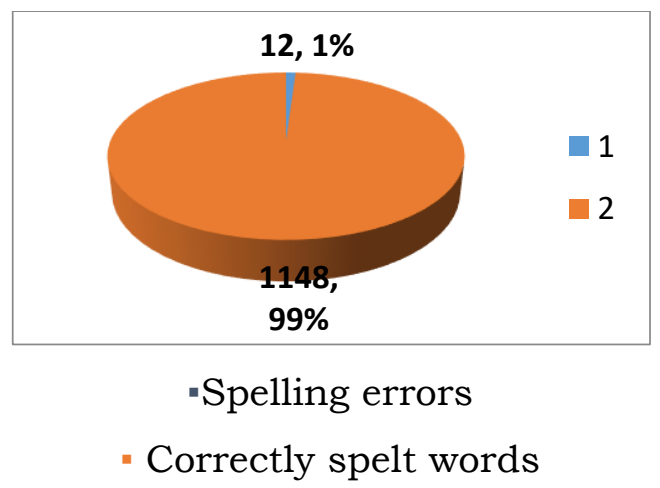

Figure 5. Instances of spelling errors made by the students of the international school

There were certain noteworthy limitations which emerged while analyzing the relevant data. Apart from the spelling errors, there were several missing punctuation marks such as apostrophes as in the case of 'parents' instead of 'parents" and 'dont' instead of 'don't'. Capitalization too was misused by a few. Yet, such errors had to be ignored as they did not fall directly under the misspelling category.

Further, some of the students had felt that writing in SMS discourse was unlike the actual typing as the latter gave a different feel when touching the keyboard of a mobile phone. They 
further stated that the way their fingers tackled the typing differed from how they controlled their hand while writing. Their argument was that they had to be conscious while producing the SMS discourse in written form as they normally do not use a pen when text messaging.

As mentioned previously, four English Literature teachers answered a questionnaire comprising of 5 open ended questions based on their teaching experiences. They were requested to mention their opinions specifically on students who are in the habit of using abbreviated English terms when text messaging.

Three of the teachers felt that the standard of spelling of their students varied from "weak" to "very good." One agreed that carelessness is a weakness common among several students adding that the avid readers are more careful in writing. Another maintained that the focused and motivated students "do well" while few are distracted due to various reasons which she did not mention. An Advanced Level Literature teacher stated that the standard of spelling of her students is generally satisfactory since only a selected few choose English Language and Literature for the Advanced Level Examination.

Regarding common spelling mistakes, three teachers commented on the mixing up of writing the plural form and possessive nouns as in 'cats' - 'cat's' and 'parents' - 'parents". The following tables show how many attributed the spelling mistakes to other reasons and not to SMS language.

Table 7. Teachers who mentioned the mixing up of writing the plural form and possessive nouns

\begin{tabular}{|l|c|}
\hline Number of teachers answered the questionnaire & 4 \\
\hline $\begin{array}{l}\text { Numbers of teachers mentioned writing the plural form } \\
\text { and possessive nouns }\end{array}$ & 3 \\
\hline $\begin{array}{l}\text { Number of teachers did not mention writing the plural } \\
\text { Form and possessive nouns }\end{array}$ & 1 \\
\hline
\end{tabular}


Table 8. Teachers who mentioned the confusion of 'there', 'their' and 'they're'

\begin{tabular}{|l|l|}
\hline Number of teacher answered the questionnaire & 4 \\
\hline Number of teachers mentioned 'there', 'their', 'they're' & 3 \\
\hline Number of teachers did not mention 'there', 'their', 'they're' & 1 \\
\hline
\end{tabular}

Two teachers also spoke of doubling certain letters such as '1' and 't' as in 'careful' instead of 'careful' and 'writing' instead of 'writing' as common spelling errors.

Table 9. Teachers who mentioned the unnecessary doubling of letters

\begin{tabular}{|l|c|}
\hline Number of teachers answered the questionnaire & 4 \\
\hline Number of teachers mentioned doubling letters & 2 \\
\hline Number of teachers did not mention doubling letters & 2 \\
\hline
\end{tabular}

Other significant mistakes that were mentioned were the common use of 'dose' - 'does', 'woman' - 'women', 'are' - 'our', 'beutiful' 'beautiful' and 'charachter' - 'character'.

Two teachers spoke of two other noteworthy spelling mistakes and they were 'cos' - 'because', 'wanna' - 'want to' and 'gonna' - 'going to'. One of them even referred to them as slang language.

As for their criteria in marking answers which contain spelling errors, two of them said that they are quite particular about them and reduce marks for such mistakes while the other two stated that they are concerned about the spelling but give more preference to the content.

There were certain limitations as well since a few external conditions had to be imposed in order to limit the scope of the study due to time constrains. For instance, the particular schools and the respective teachers were selected solely on accessibility. This led to the exclusion of students representing government 
schools. Further, the selected student population was small (twenty-six in number) since they were exclusively learning under the teachers who were approached as respondents.

\section{Results and Discussion}

The list of shortened words given in Table 1 exhibits how the commonly used English words have at least one SMS counterpart. Though the passage contains only 145 words, 49 abbreviated terms had been used by the students while transcribing them to SMS discourse. Further, if all use the same shortened forms for the particular English words, one could assume that they are quite conversant in the generally used abbreviated terms of SMS discourse. As a result, the SMS terms should appear more frequently among the spelling mistakes they have made.

According to Table 2, the total number of spelling errors made by all the students is 106 .Yet out of those, only 50 mistakes were identical to their SMS counterparts. This proves that most of the time when a student made a mistake in spelling, it did not resemble its SMS counterpart.

Table 3 indicates that out of the fifty spelling mistakes that were similar to their SMS equivalents only one word resembled the typical SMS language namely 'adolsnce' and that too was made by only one student. This evidently proves that though the selected teenagers are in the habit of using the SMS discourse while text messaging, their usual spelling mistakes do not resemble it. As mentioned by Seda (2013), this is a contrast to the public belief of SMS language leading to the deterioration of spelling. Proving the affirmation of Drouin \& Davis (2009) that language learnt over time is not easily forgotten, the chosen teenagers did not get the SMS discourse mixed up with the English terms they used in the classroom when producing the two texts. This further proved the findings by Hogan, Gilbert, Leckington \& Morris (2012) which is that students are capable of switching from SMS language to the formal English they use in their studies when necessary. Certain students made spelling mistakes due to confusion of context and even because of carelessness. Such mistakes cannot be attributed to the influence of the abbreviated words used in texting as there is no visible resemblance between the two. 
The general belief among the teachers was that the motivated and the focused students always made less spelling mistakes. They also agreed that reading played a key role in influencing good spelling. Further, selecting English by choice seems another reason behind making fewer mistakes as confirmed by the Advanced Level teacher. The information provided by these teachers regarding the common spelling errors their students make prove that most of them are related to the confusion of various grammatical and other language rules. As shown on Table $7,75 \%$ percent of them believed that their students mix up the writing of plural form and possessive nouns. The examples they provided for this error are not even remotely connected to SMS language. The situation is similar in getting confused with 'there', 'their' and 'they're'. The mixing up of 'does' - 'dose' and 'woman' 'women' are instances where the order of letters is mistaken whereas the mistake of 'are - 'our' is related to a confusion in phonetics.

However, 'cos', 'wanna' and 'gonna' which were mentioned by two of the teachers are terms which resemble the features of SMS discourse. Yet, only 'want to' appeared in the chosen passage. Though 'wanna' was used by many students in their transcription in SMS discourse, none of them used it or made an identical spelling mistake while re-writing it in unabbreviated English. As such, this paper refrains from commenting about the frequency of the particular error.

According to the teachers, the marking schemes of English Language contain a category for spelling. Therefore, making a least number of mistakes is definitely beneficial for the student.

The students who represented the international school made a lesser number of spelling mistakes than the students from the local private schools. This could be because the former followed all their subjects in English Language while the latter learned certain or more of the subjects in their mother tongue depending on the stream they follow. However, this is a topic that needs further investigation.

In general, a majority of the spelling mistakes have been made due to either carelessness, confusions over grammatical rules or mixing up of letters. The minute amount of the usage of SMS 
discourse in the unabbreviated English transcription proves that the habit of text messaging does not affect teenage spelling in a crucial manner. However, it must be mentioned that some of the students commented that they were slightly conscious of transcribing in SMS discourse with the use of a pen as it felt different to the usual usage of keyboard of a cellular phone which in fact is a limitation of this study.

\section{Conclusions}

The results proved that the majority of the spelling mistakes are made due to carelessness, confusions over grammatical rules and mixing up of letters which are hardly connected to the SMS discourse. The teachers affirmed that most students are capable of adjusting their writing styles according to the context they are written in. The students too confirmed this view.

This study was conducted within a limited group in a specific socio-economic space. Therefore, further studies are recommended to be conducted with broader groups on the same topic and also on the effects of the SMS discourse on teenage vocabulary, grammar and punctuation marks which are critical components of literacy.

The findings that were brought forward through this paper would hopefully throw a positive light on the use of text messaging which has become a necessity in the world today.

\section{References}

Bates, D. (2015). Is Your Teenager Addicted to their Mobile? 25\% are 'Almost Constantly' on their Phones. Retrieved from http: / / www.dailymail.co.uk/sciencetech/article3038496/Is-teenager-addicted-mobile-25-constantlyphones.html

Blanchard, J., \& Moore, T. (2010). The Digital World of Young Children: Impact on Emergent Literacy. Retrieved from http: / /www.pearsonfoundation.org

Cooper, L. (2005). Developmentally Appropriate Digital Environments for Young Children, Library Trends. 
Retrieved from

https://www.ideals.illinois.edu/bitstream/handle/2142/ 3477 / Cooper_Developmentally.pdf?sequence $=2 \&$ isAllowe $\mathrm{d}=\mathrm{y}$

Drouin, M., \& Davis C. (2009). R u txting? Is the Use of Text Speak Hurting Your Literacy? Retrieved from http: / /journals.sagepub.com/doi/pdf/10.1080/1086296 0802695131

Hogan, B., Gilbert, E., Leckington, M., \& Morris, C. (2012). Text Messaging: The Effects on Our Society. Retrieved from http://chrislmorris.files.wordpress.com

McElroy, J. (n. d.). Texting and Literacy. Retrieved from http: / / apcentral.collegeboard.com/apc/public/preap/tea chers_corner/45200.html

Mendis, D. (2006). Situating SMS (Short Message Service) Discourse. Retrieved from http://www.dlib.pdn.ac.lk

Seda, M. M. (2013). Students' Use of Text-Messaging and Their Learning Experiences. Retrieved from http://www.nssa.us/tech_journal/volume_2-3/vol23_article7.htm 